\title{
Observatório da Saúde no Legislativo: as proposições em saúde no âmbito do Congresso Nacional. Brasil (2011-2012). ${ }^{1}$
}

The Observatory for Health in the Legislative Power: the health propositions in the National Parliament - Brazil (2011-2012)

Observatorio de la Salud en el Poder Legislativo: las propuestas en materia de salud en el marco del Congreso Nacional - Brasil (2011 - 2012)

\section{Ivan Pricken de Bem}

Bacharel em Gestão em Saúde Coletiva. Pesquisador colaborador do Programa de Direito Sanitário da Fundação Oswaldo Cruz. Brasília, Brasil.

\section{Mauro Niskier Sanchez}

Médico Veterinário, Mestre e Doutor em Epidemiologia. Professor adjunto do Departamento de Saúde Coletiva da Faculdade de Ciências da Saúde da Universidade de Brasília. Brasília, Brasil.

Resumo: O Observatório da Saúde no Legislativo (OSL) é um espaço virtual (observatorio.fiocruz.br) constituído por um banco de dados públicos permanente, sediado na Fundação Oswaldo Cruz-Brasília, destinado ao acompanhamento das proposições legislativas de interesse para a saúde em tramitação no Congresso Nacional brasileiro e oferecimento gratuito das informações mais relevantes sobre elas. A 54를 Legislatura iniciou-se no ano de 2011 e, desde então, novas proposições foram sendo apresentadas pelo novo corpo político do Congresso Nacional, renovado por eleições. O objetivo deste artigo é apresentar resultados de pesquisa realizada nas bases de dados da Câmara dos Deputados e do Senado Federal quanto às proposições legislativas relativas à saúde e acompanhar sua tramitação e evolução no período de 2011 e 2012 . No período estudado, constatou-se que cerca de $10 \%$ das proposições apresentadas foram relativas à saúde, tendo a maioria delas relação com álcool e drogas. Com o nascimento do Observatório, a população ganha poder fiscalizador e apoiador nas políticas de saúde. Esse projeto visa, também, empoderar o cidadão ao socializar informações acerca do seu direito, possibilitando, assim, o trinômio conhecer-exigir-vivenciar.

Palavras-chaves: Produção normativa em saúde, Brasil; legislação sanitária, Brasil; políticas públicas de saúde, Brasil.

Resumen: El Observatorio de la Salud en el Poder Legislativo (OSL), es un espacio virtual (observatorio.fiocruz.br) constituido por un banco de datos públicos permanente, alojado en la Fundación Oswaldo Cruz-Brasilia, destinado al acompañamiento de los proyectos legislativos de interés para la salud en tramitación en el Congreso Nacional brasileño y al ofrecimiento gratuito de las informaciones más relevantes sobre las proposiciones legislativas en materia sanitaria. La 54른 Legislatura se inició en el año 2011 y nuevas propuestas fueron presentadas por el nuevo cuerpo

\footnotetext{
${ }^{1}$ Projeto de pesquisa financiado pelo Conselho Nacional de Desenvolvimento Científico e Tecnológico (CNPq), do Governo Brasileiro.
} 
político del Congreso Nacional, renovando por elecciones. El objetivo de este artículo es investigar en las bases de datos de la Cámara de los Diputados y del Senado Federal proposiciones legislativas relativas a la salud y acompañar su tramitación y evolución en el período de 2011 y 2012 . En el período estudiado, se constató que, de todas las proposiciones presentadas, cerca del $10 \%$ son relacionadas a la salud, teniendo la mayoría de ellas relación con el alcohol y las drogas. Con la creación del Observatorio, la población ganó poder fiscalizador y de participación en la formulación de las políticas de salud.

Palabras-clave: Producción normativa en salud, Brasil; legislación sanitaria, Brasil; políticas públicas de salud, Brasil.

Abstract: The Observatory for Health in the Legislative Power is a virtual space (observatório.friocruz.br) built by a permanent public database, based at Fundação Oswaldo Cruz-Brasília, aimed to follow the ongoing legislative bills addressed to public health in the Brazilian Parliament and to offer free relevant information about the legislative propositions on sanitary subject. The 54ํ Parliamentary Term began on the year of 2011 and new propositions were presented by the new political body of the national Parliament, renewed with election. The objective of this article is to present results of researches done in the Federal Senate and Chamber databases about the legislative propositions related to health and to follow its issuing and evolution in the 2011 and 2012 period. During the studied period, it was found that health was the subject of $10 \%$ of all presented proposals and that its majority were related to alcohol and illicit drugs. With the creation of the Observatory, the population gains the oversight and supporter power on health policies. This project aims, not only to facilitate the access to what it is proposed by the legislators, but also to empower of the citizens by giving them the knowledge of their rights, which enables the trinomial know-demand- experience.

Keywords: Rule making, Brazil; health legislation, Brazil; health public policies, Brazil.

\section{Introdução}

A Constituição Federal de 1988 garantiu, em seu texto, o direito fundamental à saúde a todos os brasileiros e estrangeiros regulares no país ${ }^{2}$.

Sendo a saúde um direito fundamental, está associado à dignidade humana, principal pilar para a garantia dos direitos fundamentais. E não se pode pensar em dignidade sem pensar na saúde porque dela depende a vida.

Sarlet (1988) define a dignidade da pessoa humana como

[...] a qualidade intrínseca e distintiva de cada ser humano que o faz merecedor do mesmo respeito e consideração por parte do Estado e da comunidade, implicando, neste sentido, um complexo de direitos e deveres fundamentais que assegurem a pessoa tanto contra todo e

\footnotetext{
${ }^{2}$ A afirmação vem da força da palavra todos, do artigo 196 da CF/88: "A Saúde é direito de todos ..." Todos são os brasileiros e os estrangeiros regulares no território nacional, conforme o caput do artigo $5^{\circ}$ do mesmo diploma.
} 
qualquer ato de cunho degradante e desumano, como venham a lhe garantir as condições existenciais mínimas para uma vida saudável.

(Sarlet, 1988, p.60)

Nesse sentido, a efetividade do direito à saúde é uma condição para a existência digna. Assim, pode-se dizer que a proteção à saúde (como condição de uma existência digna de qualquer cidadão) torna-se um dos mais relevantes pilares dos direitos fundamentas e a Constituição Federal de 1988 não só estabeleceu isso claramente como descreveu o modo pelo qual o Estado deve assegurar a sua garantia.

Se a dignidade é um dos pilares da República, conforme a Constituição expressa no art. $1^{\circ}$, concretizar o direito à saúde é, também, respeitar o modelo republicano. Ademais, a dignidade tem o escopo de preservar a própria vida humana, não apenas na condição de mera sobrevivência física do indivíduo (aspecto que assume bastante relevância no direito à saúde), mas também de uma sobrevivência que atenda aos mais elementares padrões de dignidade.

Em 1946, a Organização Mundial da Saúde (OMS) definiu a saúde como "o completo bem estar físico, mental e social e não apenas a ausência de doença ou agravos". Nesse sentido, todo ser humano deveria ter direito a um padrão de vida capaz de garantir a si e à sua família saúde e bem-estar.

Estado e governos, por intermédio das políticas públicas, ações, planos e metas buscam alcançar o bem-estar da sociedade e o interesse público e, assim, os direitos fundamentais dos cidadãos. Não é diferente quando se trata da saúde pública.

No Brasil, a saúde é direito de todos e dever do Estado, garantida pelo Sistema Único de Saúde (SUS) a todos os cidadãos. O sistema é regido por diversos princípios, tendo a participação social como basilar e democrática diretriz constitucional, possibilitando ao cidadão o exercício do seu papel de fiscalizador da execução das políticas públicas para a saúde.

Para formular as políticas públicas de saúde no país há esforços do Estado e de governos, a participação da sociedade, de setores da economia, de universidades, 
instituições científicas, mas especialmente dos Poderes instituídos: Legislativo, Executivo e Judiciário ${ }^{3}$.

O Poder Legislativo federal é um formulador de políticas públicas, inclusive sanitárias. Representado pelo Congresso Nacional, esse poder legiferante do Estado, embora detentor do monopólio da produção legal no Brasil, não tem acompanhado sua própria produção legislativa em saúde, nem controlado a eficiência e a eficácia do processo legislativo respectivo orientado por uma longa tramitação (Romero, 1998).

Delduque (2011) descreve que:

[...] tanto na Câmara dos Deputados como no Senado Federal inexiste um sistema de organização de série histórica da atividade legislativa e parlamentar que possa ser apreciado e interpretado, restando organizada tão só a atividade legislativa a partir de 2001. (Delduque, 2011, p.159)

Sem uma série histórica devidamente sistematizada, as proposições legislativas em saúde se perderam na história republicana e parlamentar do país.

Foi só em 2005, durante o Simpósio sobre Política Nacional de Saúde, realizado na Câmara dos Deputados, que instituições de saúde de todo o Brasil recomendaram a construção de meios acessíveis para o acompanhamento da tramitação das proposições legislativas em saúde, tendo como propósito central a mobilização da sociedade organizada para interação democrática com o Poder Legislativo no que se refere à matéria específica da saúde.

$\mathrm{Na}$ 54a Legislatura $^{4}$ (2010 a 2014), novas proposições vêm sendo apresentadas pelo atual corpo político do Congresso Nacional, renovado com as últimas eleições de 2010 que levaram às urnas mais de 135 milhões de brasileiros (TSE, 2010).

Dessa necessidade de acompanhamento legislativo em saúde, nasceu o projeto Observatório da Saúde no Legislativo (OSL), um espaço virtual constituído por um banco de dados públicos permanente que busca democratizar ainda mais a saúde no Brasil dando à sociedade o direito de fiscalizar, cooperar e até intervir nas ações do Poder Legislativo e Executivo.

\footnotetext{
${ }^{3}$ O Poder Judiciário tem sido um grande formulador de políticas públicas por meio de decisões judiciais sobre saúde, o que acaba por intervir no processo de constituição de uma política. Deve ser antes um poder garantidor das políticas estabelecidas e jamais um formulador.

${ }^{4}$ A legislatura compreende o período de quatro anos, coincidindo sua duração com a dos mandatos dos deputados.
} 
O OSL busca mapear e disponibilizar na base de dados da Câmara dos Deputados e do Senado Federal, informações sobre a tramitação de proposições ${ }^{5} \mathrm{em}$ saúde, constituídas em:

- $\quad$ Projetos de Lei (PL): proposição destinada a regular matéria inserida na competência normativa da União sendo uma das atribuições essenciais do Congresso Nacional;

- Projetos de Lei Complementar (PLC): proposição destinada a regulamentar normas da Constituição;

- Medidas Provisórias (MP): ato normativo exclusivo do Presidente da República, com peso de lei, que pode ser adotadas em caso de urgência e relevância. Dependem de aprovação do Congresso Nacional para transformação definitiva em lei;

- $\quad$ Proposta de Emenda à Constituição (PEC): proposição destinada a alterações ao texto constitucional vigente.

O projeto do Observatório possibilita ao cidadão pesquisar e se informar sobre os mais variados tipos de propostas que tenham por objeto a saúde, desde a alimentação e nutrição até o financiamento do sistema público brasileiro. Sua missão é fazer com que a população, de forma direta ou por meio de suas instâncias de representação, participe de um debate amplo sobre os temas, podendo, inclusive, intervir sobre eles.

Para Bartonelli (2005):

É preciso que todos saibam que a saúde é direito fundamental individual e coletivo e não mera concessão do poder estatal ou palavras bonitas escritas na Constituição. Exceto que a Legislação Sanitária Brasileira é muito mais avançada que a situação fática do país, o que não invalida o paradigma do conceito de saúde amplo, que deve ser perseguido pelo esforço de todos os atores sociais e políticos comprometidos. (Bartonelli, 2005, p.64)

Esta é a razão do projeto que visa facilitar o acesso ao que se propõe por parte dos legisladores. Há o empoderamento do cidadão que passa a ter conhecimento do seu direito enquanto é discutido na mais alta esfera legislativa brasileira, possibilitando, assim, o trinômio conhecer - exigir - vivenciar.

Diante disso, este artigo apresentará os resultados e discutirá aspectos relevantes do OSL, que mapeou proposições legislativas de interesse da saúde na

\footnotetext{
${ }^{5}$ Proposição é a denominação genérica de toda matéria submetida à apreciação do Senado Federal, da Câmara dos Deputados
} 
base de dados do Senado Federal e Câmara dos Deputados, nos anos de 2011 e 2012, período inicial da 54른 Legislatura brasileira.

\section{Metodologia}

Trata-se de um estudo descritivo exploratório, em bancos de dados secundários disponível na internet pelo site observatorio.fiocruz.br.

Para Raupp (2012), os estudos exploratórios são utilizados quando pouco se sabe sobre um assunto. Por meio deste estudo, busca-se conhecer mais a fundo sobre determinados temas, de forma a deixá-los mais claros e com opiniões precisas.

Relacionados as pesquisas descritivas o autor destaca que esse tipo de pesquisa em sua essência, busca comparar, identificar e relatar aspectos de uma determinada população utilizando como ferramentas importantes técnicas estatísticas.

Foram analisados os seguintes tipos de proposições: projetos de lei (PLS, PLC e $\mathrm{PL}$ ), propostas de emenda à Constituição (PEC), projetos de lei complementar (PLP) e medidas provisórias sobre matérias de saúde, propostas de janeiro de 2011 a dezembro de 2012. As demais espécies normativas foram descartadas por se relacionarem a fiscalização e a matérias internas do Congresso Nacional.

Os 37 descritores utilizados (em anexo) como critério de busca foram predeterminados pelo próprio Observatório, por serem considerados abrangentes englobando, o máximo possível, o tema saúde, ações e serviços.

Ressalta-se que, após a coleta de dados brutos no banco de dados do OSL, as informações foram tabuladas em Planilha Eletrônica Microsoft Excel para posteriormente gerar resultados e análises.

Os achados foram sistematizados em: 1) Total de proposições legislativas no período; 2) Proposições distribuídas por categoria; 3) Análises sobre o tema mais legislado e os dois menos frequentes no Congresso Nacional.

Foram escolhidos para análise os temas mais e menos legislados no período para elucidar os fenômenos legislativos em saúde, onde proposições legislativas aparecem por meio de representações ou acompanhando das necessidades da sociedade, mutantes com o passar dos anos e governos. 


\section{Resultados e discussão}

Ao todo, foram apresentadas 7.076 propostas de leis que abrangeram assuntos como justiça e cidadania, assuntos sociais, econômicos dentre outros.

Relativos à saúde, foram apresentadas 1.531 proposições, o que corresponde a $9,96 \%$ do total. Os números mostram que a saúde é tratada como prioridade pelo Poder Legislativo brasileiro. O alto percentual de proposições legislativas sobre saúde nesses dois anos é indício de que este tema social é preocupação dos parlamentares brasileiros, como demonstra a Tabela 1.

Tabela 1- Proposições legislativas apresentadas às duas Casas do Congresso Nacional. Brasil, 2011-2012.

\begin{tabular}{ccc}
\hline Ano & Total de proposições & Proposições em saúde \\
\hline 2011 & 4371 & $932(21,3 \%)$ \\
2012 & 2705 & $599(22,1 \%)$ \\
\hline Total & 7076 & $1531(21,6 \%)$
\end{tabular}

Fonte: Observatório da Saúde no Legislativo

A saúde como direito social tem grande apelo da sociedade em épocas eleitorais e ganha como destaque o elevado número de proposições elaboradas e apresentadas no início da legislatura (2011). Tal condição coincide com a posse dos congressistas recém-eleitos, tanto daqueles que iniciam sua carreira política quanto aqueles que estão em mandatos consecutivos. É o momento de dar ao eleitor respostas e satisfação por meio da proposição de projetos de lei, em sua maioria de caráter social, com destaque a saúde, dando maior visibilidade junto à população.

\section{1 Álcool, tabaco e outras drogas}

$\mathrm{Na}$ categorização das proposições, o tema "álcool, tabaco e outras drogas" foi abordado em $9,3 \%$ dos projetos, demonstrando a preocupação nacional no combate a drogas e outros entorpecentes como demonstra a Tabela 2.

Em estudo anterior realizado com dados do OSL sobre os projetos apresentados na 53을 Legislatura (2007-2010), Silva (2012) constatou que as proposições legislativas em saúde relacionados a esse tema propunham mudanças principalmente na legislação do álcool e do tabaco. Poucos projetos de lei tratavam de outras drogas especificas como a maconha e o crack. 
Tabela 2 - Proposições legislativas em matéria de saúde apresentadas às duas Casas do Congresso Nacional, segundo a matéria. Brasil, 2011-2012.

\begin{tabular}{|c|c|c|}
\hline Assuntos das proposições & Total & $\%$ \\
\hline Álcool, tabaco e outras drogas & 142 & 9,27 \\
\hline Indenizações, isenções de impostos, benefícios & 131 & 8,56 \\
\hline Sistema Único de Saúde & 123 & 8,03 \\
\hline Medicamentos, vacinas, insumos, produtos para a saúde & 115 & 7,51 \\
\hline Doenças crônicas não-transmissíveis & 97 & 6,34 \\
\hline Vigilância sanitária & 93 & 6,07 \\
\hline Serviços de saúde & 77 & 5,03 \\
\hline Trabalho em saúde (profissões/profissionais) & 71 & 4,64 \\
\hline Criança e adolescente / escolar & 68 & 4,44 \\
\hline Propaganda & 64 & 4,18 \\
\hline Políticas, planos, programas e projetos & 54 & 3,53 \\
\hline Saúde suplementar & 54 & 3,53 \\
\hline Alimentação e nutrição & 46 & 3,00 \\
\hline Saúde de grupos populacionais específicos & 44 & 2,87 \\
\hline Mulher & 42 & 2,74 \\
\hline Pessoa com deficiência & 40 & 2,61 \\
\hline Câncer & 40 & 2,61 \\
\hline Saúde reprodutiva & 40 & 2,61 \\
\hline Saúde mental & 36 & 2,35 \\
\hline Vigilância epidemiológica e ambiental & 36 & 2,35 \\
\hline Financiamento & 35 & 2,29 \\
\hline Saúde do trabalho (saúde do trabalhador) & 35 & 2,29 \\
\hline Causas externas de mortalidade/morbidade & 31 & 2,02 \\
\hline Sangue, outros tecidos, células e órgãos & 30 & 1,96 \\
\hline Terapias e exames & 29 & 1,89 \\
\hline Efemérides & 25 & 1,63 \\
\hline Doenças infecciosas e parasitárias & 18 & 1,18 \\
\hline Saneamento & 17 & 1,11 \\
\hline Biossegurança & 16 & 1,05 \\
\hline Ciência e tecnologia (OGM, pesquisa) & 14 & 0,91 \\
\hline Bioética & 13 & 0,85 \\
\hline Idoso & 13 & 0,85 \\
\hline Saúde bucal & 11 & 0,72 \\
\hline Administração e planejamento & 8 & 0,52 \\
\hline Transplantes & 8 & 0,52 \\
\hline DST e aids & 7 & 0,46 \\
\hline Aborto & 6 & 0,39 \\
\hline Indígena & 1 & 0,07 \\
\hline
\end{tabular}

Fonte: Observatório da Saúde no Legislativo 
Podemos observar que em 2011-2012 as casas legislativas abordam ainda a questão do álcool, relacionada principalmente à propaganda e à direção automotiva.

A Organização Mundial de Saúde (OMS) estimou que, em 2004, 2 bilhões de pessoas em todo o mundo consumiam bebidas alcoólicas (OMS, 2007). As relações entre consumo de álcool, acidentes e violência são reais e se mostram complexas envolvendo fatores individuais e ambientais (Acselrad, 2012).

Melcop (2011) vai mais fundo ao afirmar que, embora as bebidas alcoólicas possam ser consumidas sem maiores problemas, dependendo da dose, frequência e quantidade, a associação álcool e volante se somam negativamente e "ferem princípios básicos da democracia e da cidadania, com resultados danosos para a coletividade" (Melcop, 2011, p.89).

Esses danos são gerados principalmente em sociedades onde o automóvel particular é o meio de transporte mais utilizado e o consumo de álcool, além de ser tolerado, é estimulado (pela publicidade), resultando em um comportamento considerado socialmente aceito (Ross, 1992).

No Brasil, a propaganda de bebidas alcoólicas e tabaco é regulada pelas Leis $\mathrm{n}^{\circ \mathrm{s}}$ 9.294, de 1996, e 10.167, de 2000. Essas leis impuseram limites e restrições ao uso e divulgação de produtos como o cigarro e as bebidas alcoólicas com mais de 13 GL, excluindo assim, cervejas e vinhos que representam $61 \%$ e $25 \%$ do consumo alcoólico no país respectivamente (Laranjeira, 2007).

Apesar dessa regulação, o Congresso ainda se mostra fortemente atento às questões relacionadas ao álcool. O deputado Romero Rodrigues em seu PL no 3308, de 2012, associou o consumo de álcool e direção nas rodovias federais e propôs nova redação para a antiga Lei $n^{\circ}$ 9.294, de 1996. O projeto de lei propunha que todos os estabelecimentos que comercializam bebidas alcoólicas às margens das rodovias federais devem afixar advertências escritas com a mensagem de que é crime dirigir sob a influência de álcool ou de qualquer outra substância psicoativa que determine dependência (BRASIL. Câmara dos Deputados. Projeto de Lei ㄲo 3308, de 29 de fevereiro de 2012).

$\mathrm{Na}$ justificação, o propositor usa as estatísticas e estudos antigos de mortalidade feitos pelo Departamento Nacional de Trânsito em 1997 como argumento para defender seu PL. Dados ultrapassados como esses enfraquecem os argumentos do legislador, visto que desde 2008, com o advento da Lei Seca, o número de 
internações e óbitos em todo o país, decorrentes de acidentes de transito causados por motoristas embriagados, tiveram redução de 20\% (Brasil, 2009).

Mesmo sendo proposto em 2011, o projeto de lei permanece ainda sem previsão para votação.

\subsection{Saúde Indígena}

Nos temas menos abordados, observa-se que políticas consolidadas como as de controle às DST e aids, de Saúde Bucal e de transplantes foram levantados timidamente no congresso. Já outras como Saúde Indígena foram lembradas no Poder Legislativo apenas uma vez em dois anos.

O Subsistema de Atenção à Saúde Indígena foi criado em 1999 pela Lei no 9.836, de 1999, que garantiu aos povos indígenas um sistema de saúde baseado em suas especificidades étnicas e culturais adotando um modelo diferenciado de proteção, promoção e recuperação da saúde.

Essa política de descentralização do atendimento reduziu, mediante convênios assinados com prefeituras e instituições da sociedade civil, a ação estatal direta com a implementação de 34 Distritos Sanitários Especiais Indígenas (DSEls), gerando assim alguns resultados positivos para a gestão e prestação da assistência.

Durante muitos anos, o Subsistema de Saúde Indígena do Sistema Único de Saúde foi gerido pela Fundação Nacional de Saúde (Funasa), que era constantemente alvo de denúncias ligadas a corrupção e deficiências no atendimento. Foi só em 2010, com reivindicações do movimento indígena, que a gestão da saúde indígena passou a ser administrada por uma secretaria especifica vinculada diretamente ao Ministério da Saúde.

Atualmente os DSEls são geridas pela Secretaria Especial de Saúde Indígena (Sesai), sendo delimitados a partir de critérios epidemiológicos, geográficos e etnográficos. Cada DSEI possui um conjunto de equipamentos que permite a realização do atendimento nos casos mais simples. A alta complexidade fica a cargo de hospitais regionais mais próximos dos distritos.

Apesar dos avanços significativos, a saúde indígena ainda é dirigida por um arco normativo infralegal (regidos por decretos e portarias).

\subsection{Aborto}

O aborto é o segundo tema menos legislado no período. 
O debate sobre o aborto cresceu nos últimos anos no Brasil, com lançamentos de pesquisas e intensificação dos debates nos Poderes Judiciário e Legislativo desde o ano 2007, quando houve a primeira audiência pública que discutiu o PL № 1.135, de 1991, dos deputados Eduardo Jorge e Sandra Starling que defendiam a descriminalização do aborto (BRASIL. Câmara dos Deputados. Projeto de Lei ${ }^{\circ}$ 1135, de 28 de maio de 1991).

A primeira Pesquisa Nacional Sobre o Aborto (PNA) realizada no Brasil concluiu que o aborto é tão comum no país que, ao completar quarenta anos, mais de uma em cada cinco mulheres já fez aborto. A religião não se mostrou um fator importante para a realização do procedimento, já que a maioria dos abortos foram feitas por católicas, protestantes e evangélicas. O estudo evidenciou, ainda, que grande parte das internações pós-aborto poderiam ter sido evitadas se essa prática não fosse tratada como atividade clandestina e o acesso aos medicamentos seguros para aborto fosse garantido. (Diniz \& Medeiros, 2010).

Através dos resultados colhidos no OSL, observou-se que quatro das seis proposições desenvolviam posições parcialmente favoráveis ao aborto, ou seja, foram propostos assistência à saúde ou auxílios financeiros àquelas mulheres vítimas de estupro ou grávidas de bebês anencéfalos.

Mesmo com a legalização do aborto de anencéfalo em abril 2012 pelo Supremo Tribunal Federal (STF), senadores se mostram descontentes com o rumo que este tema vinha tomando. O PLS no 287 , de 2012, criminaliza a prática da interrupção de gravidez em razão de diagnóstico de anencefalia com pena de três anos de detenção. Em sua justificação, o propositor da matéria defende os costumes cristãos, os princípios constitucionais da inviolabilidade da vida humana e a Declaração Universal do Direitos Humanos que define que 'todo o indivíduo tem direito à vida' (art. $\left.3^{\circ}\right)$ (BRASIL. Senado Federal. Projeto de Lei Senado oㅡ 287, de 7 de agosto de 2012).

O tema do aborto é delicado e tenta avançar no campo das políticas públicas. Essa questão bioética esbarra na forte influência das bancadas religiosas, que a veem como um problema de cunho individual e não de saúde pública. Segundo Menezes e Aquino (2009), o Estado brasileiro deve reafirmar a sua laicidade e revisar sua legislação vigente sobre o aborto para "favorecer a implementação de ações que assegurem maior autonomia de mulheres e homens nas questões reprodutivas e thes 
permitam vivenciar suas escolhas sem riscos à saúde" (Menezes \& Aquino, 2009, p. s201).

\subsection{Considerações gerais sobre o processo legislativo em saúde}

Relacionados a aprovação de leis, observou-se que, até a metade da 54a Legislatura, projetos de lei apresentados no período de 2007 a 2009 eram amplamente discutidos, aprovados ou arquivados. Enquanto os de 2011 e 2012 tramitavam lentamente nas duas casas.

Uma crítica vem sendo feito ao Parlamento no que diz respeito à lentidão de suas decisões, onde se comparam a produtividade dos congressistas de acordo com o número de leis novas em vigor. Os processos legislativos são, sim, lentos e naturalmente devem ser assim, pois, numa democracia espera-se pluralidade, debates e respeito à diversidade de opiniões (Cardozo, 2009).

O tempo da aprovação de leis pode ser crucial para a preservação dos interesses dominantes da sociedade. Nesse sentido, diversas Constituições, assim como a brasileira, usam de artifícios como as medidas provisórias para que o ato de legislar não fique centrado unicamente no Poder Legislativo. E no campo da saúde, isso não foi nada diferente, pois decisões urgentes, de fato não podem esperar.

\section{Conclusão}

Diante dos resultados do Observatório da Saúde do Legislativo, vemos a preocupação, por parte dos congressistas, com o combate às drogas. Entretanto, alguns assuntos de pouco conhecimento da sociedade são tratados com pouca força no Legislativo Federal brasileiro, como foi o caso da saúde indígena que, desde a data de seu reconhecimento em 1999, não teve mais iniciativas parlamentares para aprimoramento da política do Subsistema de Atenção à Saúde Indígena.

A proposta do OSL dá suporte e segue as diretrizes que norteiam o Sistema Único de Saúde, que decretam a participação da população nas políticas públicas de saúde. Por meio de projetos de lei de iniciativa popular, os cidadãos ganham o direito de elaborar leis e de intervir nos rumos políticos do país. Sendo assim, associações, órgãos de classe, sindicatos e entidades organizadas da sociedade civil podem apresentar às Casas Legislativas sugestões, pareceres técnicos e exposições na busca de uma verdadeira saúde para todos. 


\section{Referências}

ACSELRALD, G. et al. Consumo de bebidas alcoólicas no Brasil: Estudo com base em dados secundários. Relatório de Pesquisa. Rio de Janeiro: Faculdade LatinoAmericana de Ciências Sociais, 2012. [ISBN não fornecido] [on line] Disponível em: http://www.flacso.org.br/portal/pdf/area_saude_publica_direitos_humanos/RelatorioCo nsumodoAlcoolnoBrasilFlacso05082012.pdf. Acesso em: 6 dez. 2013.

BARTOLOMEI, C. E. et al. Saúde, direito de todos e dever do Estado. Senatus, 4(1):60-65, 2005. ISSN 1678-2313

BRASIL, Ministério da Saúde. 'Lei Seca' reduz internações e óbitos em mais de $20 \%$. Brasília: Portal da saúde, 2009. [on line] Disponível em: http://portal.saude.gov.br/portal/aplicacoes/noticias/default.cfm?pg=dspDetalheNoticia \&id_area $=124 \& C O \_N O T I C I A=10320$. Acesso em: 12 nov. 2013.

BRASIL, Lei no 9.836, de 23 de setembro de 1999. Acrescenta dispositivos à Lei $\mathrm{n}^{\circ} 8.080$, de 19 de setembro de 1990, que "dispõe sobre as condições para a promoção, proteção e recuperação da saúde, a organização e o funcionamento dos serviços correspondentes e dá outras providências", instituindo o Subsistema de Atenção à Saúde Indígena. Diário Oficial [da] República Federativa do Brasil, Brasília, DF, 24 set. 1999. [on line] Disponível em: <http://www.planalto.gov.br/ccivil_03/Leis/L9836.htm>. Acesso em: 10 nov. 2013.

BRASIL. Lei $n^{\circ}$ 10.167, de 27 de dezembro de 2000. Altera dispositivos da Lei $n^{\circ}$ 9.294, de 15 de julho de 1996, que dispõe sobre as restrições ao uso e à propaganda de produtos fumígenos, bebidas alcoólicas, medicamentos, terapias e defensivos agrícolas. Diário Oficial [da] República Federativa do Brasil, Brasília, DF, 28 dez. 2000. [on line] Disponível em: < http://www.planalto.gov.br/ccivil_03/Leis/L10167.htm>. Acesso em: 12 nov. 2013.

BRASIL. Lei no 9.294, de 15 de julho de 1996. Dispõe sobre as restrições ao uso e à propaganda de produtos fumígeros, bebidas alcoólicas, medicamentos, terapias e defensivos agrícolas, nos termos do $\S 4^{\circ}$ do art. 220 da Constituição Federal. Diário Oficial [da] República Federativa do Brasil, Brasília, DF, 16 jul. 1996. [on line] Disponível em: < http://www.planalto.gov.br/ccivil_03/Leis/L9294.htm>. Acesso em: 12 nov. 2013.

BRASIL. Senado Federal. Projeto de Lei Senado o 523, de 29 de agosto de 2011. Estabelece Programa de abatimento no IRPF do gasto na compra de medicamentos de doenças que especifica e dá outras providências. Autor: Senador Alvaro Dias. Diário do Senado Federal, Brasília, DF, 30 ago. 2011, p. 35499-500. [on line] Disponível em: < http://legis.senado.leg.br/diarios/BuscaDiario?tipDiario=1\&datDiario=30/08/2011\&pagi naDireta=35499>. Acesso em: 16 nov. 2013.

BRASIL. Senado Federal. Projeto de Lei Senado no 287, de 7 de agosto de 2012. Acrescenta os arts. 128-A a 128-C ao Decreto-Lei no 2.848 , de 7 de dezembro de 1940 (Código Penal) para dispor sobre o crime de interrupção de gravidez em razão de diagnóstico de anencefalia. Autora: Senadora Maria do Carmo Alves. Diário do Senado Federal, Brasília, DF, 8 ago. 2012, p. 39664-6. [on line] Disponível em: < http://legis.senado.leg.br/diarios/BuscaDiario?tipDiario=1\&datDiario=08/08/2012\&pagi naDireta=39664>. Acesso em: 18 nov. 2013. 
BRASIL. Câmara dos Deputados. Projeto de Lei oㅜ 3308, de 29 de fevereiro de 2012. Dá nova redação ao parágrafo único do art. 3ํㅡㄹ da Lei oㅜ 9.294, de 15 de julho de 1996, que "dispõe sobre as restrições ao uso e à propaganda de produtos famígeros, bebidas alcoólicas, medicamentos, terapias e defensivos agrícolas". Autor: Deputado Romero Rodrigues. Diário da Câmara dos Deputados, Brasília, DF, 1o mar. 2012, p. 4847, col 02 . Disponível em: < http://imagem.camara.gov.br/montaPdf.asp?narquivo=DCD01MAR2012.pdf\&npagina =333>. Acesso em: 12 nov. 2013.

BRASIL. Câmara dos Deputados. Projeto de Lei n 1135, de 28 de maio de 1991. Suprime o artigo que caracteriza crime o aborto provocado pela gestante ou com seu consentimento; (liberalização do aborto); altera o Decreto-lei № 2.848, de 1940.

Deputado Eduardo Jorge. Disponível em: http://www.camara.gov.br/proposicoesWeb/fichadetramitacao?idProposicao=16299. Acesso em: 18 nov. 2013

CARDOZO, J. E. A crise do Legislativo. Estudos Avançados, 23(67):79-87, 2009. ISSN 0103-4014

DELDUQUE, Maria Célia. Observar para participar: a world wide web como instrumento para acompanhar a produção legislativa em saúde no Brasil. Em: ROMERO, Luiz Carlos \& DELDUQUE, Maria Celia (orgs). Estudos de Direito Sanitário: a produção normativa em Saúde. Brasília: Senado Federal, 2011, p. 157 a 162. ISBN 978-85-7018-387-3

DINIZ, D; MEDEIROS, M. Aborto no Brasil: uma pesquisa domiciliar com técnica de urna. Ciência \& Saúde Coletiva, 15(Supl. 1):959-966, 2010. ISSN 1413-8123.

LARANJEIRA, R. et al. I Levantamento Nacional sobre os padrões de consumo de álcool na população brasileira. Brasília: Secretaria Nacional Antidrogas, 2007. ISBN 978-85-60662-00-5

MELCOP, A.G.T. Vamos parar por aqui? Os desafios da abordagem de redução de danos nas violências no trânsito. Brasília: Ministério da Saúde, 2004. pp.85-102. ISBN 85-334-0776-9

MENEZES, Greice \& AQUINO, Estela M. L. Pesquisa sobre o aborto no Brasil: avanços e desafios para o campo da saúde coletiva. Cadernos de Saúde Pública, Rio de Janeiro, 25(Sup 2):S193-S204, 2009. ISSN 0102-311X

ORGANIZAÇÃO MUNDIAL DA SAÚDE (OMS). Youth and road safety. 2007. [on line] [ISBN não fornecido] Disponível em: http://whqlibdoc.who.int/publications/2007/9241595116_eng.pdf/. Acesso em: 1 nov. 2013.

RAUPP, F. M. \& BEUREN, I. M. Metodologia da pesquisa aplicável às ciências sociais. In: BEUREN, I.M. (Coord.). Como elaborar trabalhos monográficos em contabilidade: teoria e prática. SãoPaulo: Atlas, 2003. p. 76-97. ISBN

ROMERO, Luiz Carlos et al. Avaliação das atividades do legislativo na área de saúde pública (1995-1996). Brasília: Senado Federal, 1998 p. 7 a 8. [ISBN não fornecido]

ROSS, H. L. Confronting Drunk Driving: Social Policy for Saving Lives. New Haven: Yale University Press, 1992. ISBN 9780300058659 
SARLET, Ingo. Dignidade da Pessoa Humana e Direitos Fundamentais na Constituição Federal de 1988. (2. ed.) Porto Alegre: Livraria do Advogado, 2002. ISBN 8573488166

SILVA, M. B. O debate sobre as drogas no Congresso Nacional: Descrição e Análise quantitativa das proposições legislativas da 53른 Legislatura. Em: DELDUQUE, Maria Célia \& ROMERO, Luiz Carlos. Produção normativa em saúde: políticas setoriais e regulação. Brasília: Senado Federal, 2012, p.283 a 293. ISBN 978-85-7018-462-7

TRIBUNAL SUPERIOR ELEITORAL (TSE). Estatística de eleitorado 2010. [on line] Disponível em: http://www.tse.jus.br/eleicoes/eleicoes-anteriores/eleicoes2010/estatisticas-de-eleitorado. Acesso em: 7 nov. 2013. 